\title{
Growth Performance of Teak Plantations Managed Under Different Treatments
}

\author{
Fernando B.M.S.R. ${ }^{1}$, Subasinghe S.M.C.U.P. ${ }^{1}$ and Bandara K.M.A. ${ }^{2}$ \\ ${ }^{l}$ Department of Forestry and Environmental Science, Faculty of Applied Sciences, \\ University of Sri Jayewardenepura, Nugegoda, Sri Lanka, \\ ${ }^{2}$ Forest Research Centre, Badulla, Sri Lanka \\ *shanuka14@gmail.com
}

\begin{abstract}
Tectona grandis, commonly known as Teak, is an exotic species and is one of the most demanding and valuable timber species grown in Sri Lanka. Main factors that affect the growth of teak are site quality, planting material and silvicultural treatment applied when managing the trees as plantations. Teak plantations have been established mainly in the dry and intermediate zones of the low country. The present study was conducted with the objective of comparing the growth performance across the growth stages of young teak plantations managed under different treatment regimes.

Nine teak plantations in the intermediate zone of the low country were selected for the present study. Three different management regimes were used for the selected plantations which can be categorized as, less intensive management (LM) and two intensive management regimes (IM). Dbh and height of trees of the sample plots located at random were measured using standard methods. The tree growth records in those plantations in the past were obtained by the available data records. Timber volumes of measured trees were calculated using the allometric equation developed by Subasinghe in 2004 for Teak. One way ANOVA testwas used to compare the differences ofdbh, height and timber volume values of different plantations considered in this study.

Results indicate that dbh, height and timber volume of the IM plantation in Monaragala are significantly higher than those of other plantations across the growth stages. There are no significant differences in growth parameters and volume between state-owned plantations. There are also no significant differences between dbh, height and volume between LM and state-owned plantations.
\end{abstract}

Keywords: Teak plantations, Different treatments, Growth performance 